\title{
Daniel Chaubet, La Chronique de Savoye de Cabaret. Texte intégral
}

\section{Paola Cifarelli}

\section{Q OpenEdition}

10 Journals

\section{Édition électronique}

URL : http://journals.openedition.org/studifrancesi/9793

DOI : 10.4000/studifrancesi.9793

ISSN : 2421-5856

Éditeur

Rosenberg \& Sellier

\section{Édition imprimée}

Date de publication : 1 octobre 2007

Pagination : 419-420

ISSN : 0039-2944

\section{Référence électronique}

Paola Cifarelli, «Daniel Chaubet, La Chronique de Savoye de Cabaret. Texte intégral », Studi Francesi [En ligne], 152 (LI | II) | 2007, mis en ligne le 30 novembre 2015, consulté le 09 janvier 2021. URL : http:// journals.openedition.org/studifrancesi/9793; DOI : https://doi.org/10.4000/studifrancesi.9793

Ce document a été généré automatiquement le 9 janvier 2021.

\section{(c) (i) (9)}

Studi Francesi è distribuita con Licenza Creative Commons Attribuzione - Non commerciale - Non opere derivate 4.0 Internazionale. 


\title{
Daniel Chaubet, La Chronique de Savoye de Cabaret. Texte intégral
}

\author{
Paola Cifarelli
}

\section{RÉFÉRENCE}

DANIEl CHAUBET, La Chronique de Savoye de Cabaret. Texte intégral, Chambéry, Comp'Act, 2006, pp. 421.

1 À une époque où les humanistes, sous l'impulsion des grandes dynasties européennes, s'appliquent à retrouver les origines de l'histoire de leur nation dans la mythologie, le duc de Savoie Amédée VIII chargea Jean d'Orville, surnommé Cabaret, de célébrer la gloire de ses ancêtres dans un ouvrage qui constituera pendant longtemps le texte fondateur de l'historiographie savoisienne. La Chronique de Savoye date de 1419, trois ans seulement après l'érection de la Savoie en duché par l'empereur Sigismond de Luxembourg. Rédigée en français et transmise par trentequatre manuscrits, la Chronique est restée inédite, malgré le succès considérable dont elle doit avoir joui jusqu'à l'orée du XVI ${ }^{\mathrm{e}}$ siècle.

D. Chaubet édite le texte transmis par le manuscrit BnF, f. fr. 6164 , choisi sur la base du stemma codicum reproduit à la p. 35. La transcription est précédée par une introduction qui souligne, avant tout, les aspects originaux de cette chronique, et particulièrement la création d'un chef de ligne mythique pour la maison de Savoie: le personnage de Bérold, neveu légendaire de l'empereur Othon III, est examiné dans ses aspects littéraires, qui le mettent en rapport avec des héros de chansons de geste, mais aussi dans ses implications politiques. À ce propos, la Chronique de Cabaret valorise également l'aspect sacré de la dynastie de Savoie, à travers l'insistance sur la célèbre légende des martyrs thébéïnes et de la transmission de l'anneau de saint Maurice. Après avoir rapidement analysé la perspective sous laquelle sont peints les rapports avec les autres forces politiques contemporaines (l'Église, la France et l'Empire), D. 
Chaubet met encore en évidence l'originalité de cet ouvrage dans une perspective héraldique, mais aussi ses rapports avec les textes antérieurs sur le même sujet.

3 Le texte, organisé en 326 chapitres, couvre done l'histoire de la maison de Savoie depuis ses origines jusqu'à l'avènement d'Amédée VIII. Il est suivi d'une table des chapitres et d'un index des noms propres, qui reçoivent une glose succincte mais indispensable pour permettre aux non spécialistes de l'historiographie savoyarde de s'orienter dans le texte.

4 L'intérêt documentaire d'un tel ouvrage, souligné par la préface de Louis Terreaux, est accru par le rôle fondamental qu'il joue dans l'histoire culturelle du duché de Savoie: il s'agit en effet de la première chronique savoisienne rédigée en langue française. Témoignage de l'importance que la civilisation d'Outre-monts acquiert à l'époque, ce texte historique constitue également un précieux document pour l'histoire de l'affirmation du français comme langue de culture. Le travail méritoire de D. Chaubet rend donc accessible un matériau sur lequel on pourra se pencher même d'un point de vue linguistique. 